\title{
Effects of a digital reminiscing intervention on people with dementia and their care-givers and relatives
}

Sandra Derbring ${ }^{1 \star ~(D), ~ M e l i s s a ~ B a r b o s ~ N o r d s t r o ̈ m ² ~}{ }^{2}$ Jenny-Ann Svenningsson ${ }^{2}$, Anna Ekström³ Elias Ingebrand ${ }^{4}$, Christina Samuelsson ${ }^{5 \dagger}$, Katja Laakso ${ }^{2}$ and Margret Buchholz ${ }^{1,2}$

${ }^{1}$ DART Centre for AAC and AT, Queen Silvia Children's Hospital, Sahlgrenska University Hospital, Göteborg, Sweden, ${ }^{2}$ Institute of Neuroscience and Physiology, Sahlgrenska Academy, University of Gothenburg, Göteborg, Sweden, ${ }^{3}$ Department of Biomedical and Clinical Sciences, Linköping University, Linköping, Sweden, ${ }^{4}$ Department of Culture and Society, Linköping University, Linköping, Sweden and ${ }^{5}$ Department of Clinical Science, Intervention and Technology, Karolinska Institutet, Stockholm, Sweden *Corresponding author. Email: sandra.derbring@vgregion.se

(Accepted 8 September 2021)

\begin{abstract}
Dementia is a source of growing concern globally, and often impacts on social and communicative functioning. INdependent LIving Support Functions for the Elderly (IN LIFE) was a project carried out within the European Commission Research and Innovation programme Horizon 2020 that resulted in the development of two digital communication aids for reminiscence intervention for elderly people with dementia and their communication partners. The purpose of this intervention study was to investigate the effects on quality of life for people with dementia when using these aids. People with dementia $(\mathrm{N}=118)$ and their formal care-givers $(\mathrm{N}=187)$ and relatives $(\mathrm{N}=9)$ were given the communication aids for a period of 4-12 weeks. To assess a range of outcomes, questionnaires developed within the project were used along with the EQ-5D (European Quality of Life - 5 Dimensions) and QoL-AD (Quality of Life in Alzheimer's Disease) questionnaires. Quality of life improved among people with dementia when measured using EQ-5D $(p<0.05)$. There was also a correlation between the impact on the participants' health and wellbeing, the carers' rating of the usefulness of the digital communication aids and the care-givers' satisfaction with using technology $(p<0.05)$. These results indicate that digital communication aids may be useful in social interaction where one partner has dementia.
\end{abstract}

${ }^{\dagger}$ This paper was originally published without acknowledging the contributions of the following three authors: Anna Ekström, Elias Ingebrand, Christina Samuelsson. This has now been updated and a corrigendum published at https://doi.org/10.1017/S0144686X21001963.

$\mathrm{SD}, \mathrm{MB}, \mathrm{KL}, \mathrm{AE}$ and $\mathrm{CS}$ are responsible for the overall design of the study, and the development of instruments. $\mathrm{SD}, \mathrm{MB}, \mathrm{KL}, \mathrm{AE}, \mathrm{CS}$ and $\mathrm{EI}$ are responsible for the organisation of data collection. MBN and J-AS are responsible for the analysis and interpretation of the data and for the drafting of this article under the supervision of KL. SD and MB are responsible for revising this article for content and for getting it into a state ready for submission.

(C) The Author(s), 2021. Published by Cambridge University Press. This is an Open Access article, distributed under the terms of the Creative Commons Attribution licence (http://creativecommons.org/licenses/by/4.0/), which permits unrestricted re-use, distribution and reproduction, provided the original article is properly cited. 
Keywords: dementia; communication; digital communication aids; reminiscence intervention; quality of life

\section{Introduction}

Worldwide, 55 million people are living with dementia and it is now the 7th leading cause of mortality (Gauthier et al., 2021). Dementia has a major impact on the individual's quality of life and the symptoms can lead to communication difficulties, frustration and sadness (Clare et al., 2008; Prince et al., 2015). As the world population grows older, the number of people living with dementia is likely to double every 20 years, which will lead to one of the greatest global challenges for public health-care to solve (Prince et al., 2015).

Dementia is a collective name and a diagnosis for a set of symptoms caused by neurodegeneration affecting the ability of synapses to communicate. Depending on the location, cause and extent of the damage, the disease manifests itself in a variety of ways and to a varying degree. Common cognitive symptoms are memory problems, word-finding difficulties, anomia, and difficulty planning and performing daily life activities, as well as psychiatric symptoms such as anxiety, depression and other behavioural changes (Tang and Robinson, 2013). Overall, people with dementia often need support from their relatives or care-givers (Prince et al., 2013) and their quality of life may be negatively affected by reduced opportunities for social contact (Hoe et al., 2006).

There are several definitions of quality of life. The most widely used definition is from the World Health Organization, which describes quality of life as a state of being in full physical, mental and social wellbeing (Fayers and Machin, 2000). Another definition is HRQoL (Health-Related Quality of Life) (Sloane et al., 2005) which involves an assessment limited to the effects on a person's state of health and overall wellbeing, and how it can influence their ability to live a good life (Azoulay et al., 2008; Wolak-Thierry et al., 2014). EQ-5D (European Quality of Life - 5 Dimensions) was created by Brooks (1996) to measure HRQoL and deals with physical, mental and social functioning (Herdman et al., 2011). A further definition is disease-specific quality of life, which focuses on a particular disease or diagnosis and the aspects of a person's life that are affected most (Sloane et al., 2005). QoL-AD (Quality of Life in Alzheimer's Disease) is designed specifically for people with dementia and was developed by Logsdon, Gibbson, McCurry and Teri in 1999 (Wolak-Thierry et al., 2014).

\section{Background}

Social interaction with other people is essential for the preservation of identity and self-esteem (Pearce et al., 2002; Ericsson et al., 2011). In order to feel understood and positive, people with dementia need the opportunity to communicate with family, friends, health-care professionals and strangers (Preston et al., 2007). It is important that those around people with dementia initiate and maintain conversations to stimulate social interaction (Ericsson et al., 2011).

Quality of life increases when people with dementia attain social inclusion and have access to activities that they find meaningful (Abrahamson et al., 2012). The 
possibility to tell others about one's life and past experiences is also important as it can compensate for the loss of current abilities (Clare et al., 2008). It is common for the diagnosis of dementia to cause a lack of insight into one's difficulties, which can create frustration and a sense of hopelessness among relatives and informal care-givers (Ducharme and Geldmacher, 2011). Dementia therefore not only results in reduced quality of life for a person with the disease but also among relatives or informal care-givers (Ducharme and Geldmacher, 2011; Välimäki et al., 2016). When a person with dementia moves to a care home, relatives and informal care-givers may experience a sense of reduced responsibility and improved HRQoL (Bleijlevens et al., 2015). However, people with dementia living in care homes often experience feelings of insecurity, loss, isolation, loneliness and fear (Clare et al., 2008).

Good relationships between people with dementia and their care-givers are important to preserve wellbeing and quality of life for both parties (Clare et al., 2008). To achieve this, the care-givers and relatives need training in strategies that can create conditions where people with dementia do not feel socially isolated and instead experience improved quality of life (Bourgeois and Hickey, 2007; Smith et al., 2011).

Reminiscence intervention involves conversations about past events and experiences with the goal of reviving memories and stimulating cognition for people with dementia and improving their health and wellbeing. Reminiscence intervention can include the use of videos, images and objects, either in groups or individually. A systematic review (Woods et al., 2018) showed that reminiscence intervention did not have any clinically significant long-term effects. However, there are identified benefits of 'in the moment' enjoyment of a shared social experience and some effect on cognitive function, communication, interaction, quality of life and mood. A study by Lopes et al. (2016) showed that an individual reminiscence programme resulted in significant improvement in mental health, reduced anxiety and greater ability to access autobiographical memory for people with dementia, but further research is needed to clarify long-term effects. Reminiscence intervention can help care-givers who are competent communication partners to improve the quality of interaction with people with dementia (Bourgeois et al., 2001).

With the development of digital technology, there is greater potential for it to be used for health-related purposes. Having a digital system for reminiscence intervention in place can promote the use of reminiscence intervention as a form of therapy. It supports multiple users, and the health-care provider has the potential to store both generic material and the personal material of the people with dementia (Anderson et al., 2014). Research has shown that people with dementia and their care-givers can easily adapt to computer-based reminiscence interventions, and suggests that it is beneficial when used between people with dementia and their care-givers (Alm et al., 2004). In comparison with more traditional reminiscence interventions, such as photograph albums, multimedia interventions can increase the opportunity for shared attention and social interaction between people with dementia and their communication partners (Astell et al., 2005, 2010). The general increase in internet use has created a greater need for and interest in mobile and internet-based health and medical care applications, termed collectively as E-health (Kerkhof et al., 2016). Touchscreen devices such as tablets are commonly available and developing tablet applications is now relatively easy. This has led to a growing interest within health-care organisations in extending the use of tablets to specific target groups, such as people with dementia (Kerkhof et al., 2016). 


\section{The IN LIFE project}

This present study was part of the three-year research and development project IN LIFE (INdependent LIving Support Functions for the Elderly), carried out within the European Commission Research and Innovation programme Horizon 2020 (European Commission, 2018). Nine European countries were involved in the task of improving opportunities for elderly people to lead an efficient and independent everyday life. The two Swedish partners, Dart, a regional centre for assistive technology and augmentative and alternative communication at Sahlgrenska University Hospital, and CEDER, a dementia research centre at Linköping University, collaborated to investigate the effects of elderly people with dementia using digital communication aids in conversation with their communication partners (Astell et al., 2018; European Commission, 2018).

Two digital communication aids were developed within the context of reminiscence intervention and they can be used on any type of tablet or computer. These Web-based aids, called CIRCA and CIRCUS, were aimed for use by people who have difficulty communicating and their relatives and care-givers (University of Sheffield, 2018).

CIRCA was created to support socialisation and interaction, and it contains generic material presented within three general categories (film, photos and music) all from different time periods (Astell et al., 2010). The content presented within the categories at any given time is randomised. The randomisation varies each session to give novelty without placing a burden on the care-giver to plan and organise in advance. CIRCA builds upon software from the University of Sheffield. It has been used in previous studies for people with dementia (Gowans et al., 2004; Astell et al., 2010; Ferm et al., 2020). Results revealed that using CIRCA increased interaction for people with dementia and their care-givers. In summary, the interaction while using CIRCA was more relaxed and enjoyable, and care-givers felt that they became better acquainted with the people with dementia and that it improved their relationship (Astell et al., 2010). The IN LIFE project has transformed CIRCA into a Web application suitable for modern platforms and devices such as tablets and smartphones (see Figure 1). The project also translated the existing material from English into Swedish, and supplemented the British content with photos and music suitable for a Swedish context. The layout, however, remains very similar to previous versions.

CIRCUS is a personal digital communication aid that is designed to support memory and conversation and contains films and photos uploaded by people with dementia and their care-givers (see Figure 2). CIRCUS also has additional features. One of these is the sharing function, which means that a user can add another user of CIRCUS and then share selected photos or other items with this user. This function is designed to allow users of CIRCUS to communicate and share their experiences with care-givers who may live far away and likewise for caregivers to easily be able to add content remotely to a user they support. This allows the user to easily convey simple phrases about their personal lives and opinions to the care-givers with whom they are interacting. A study by Goffe and Karlsson (2017) found that the use of CIRCUS as a communication aid contributed to a more positive experience for people with dementia and their care-givers compared, for example, with using a photograph album. They were able to interact on more equal terms with CIRCUS, and the care-givers who participated felt that inclusion of personal material facilitated the conversation. An interaction study with three 

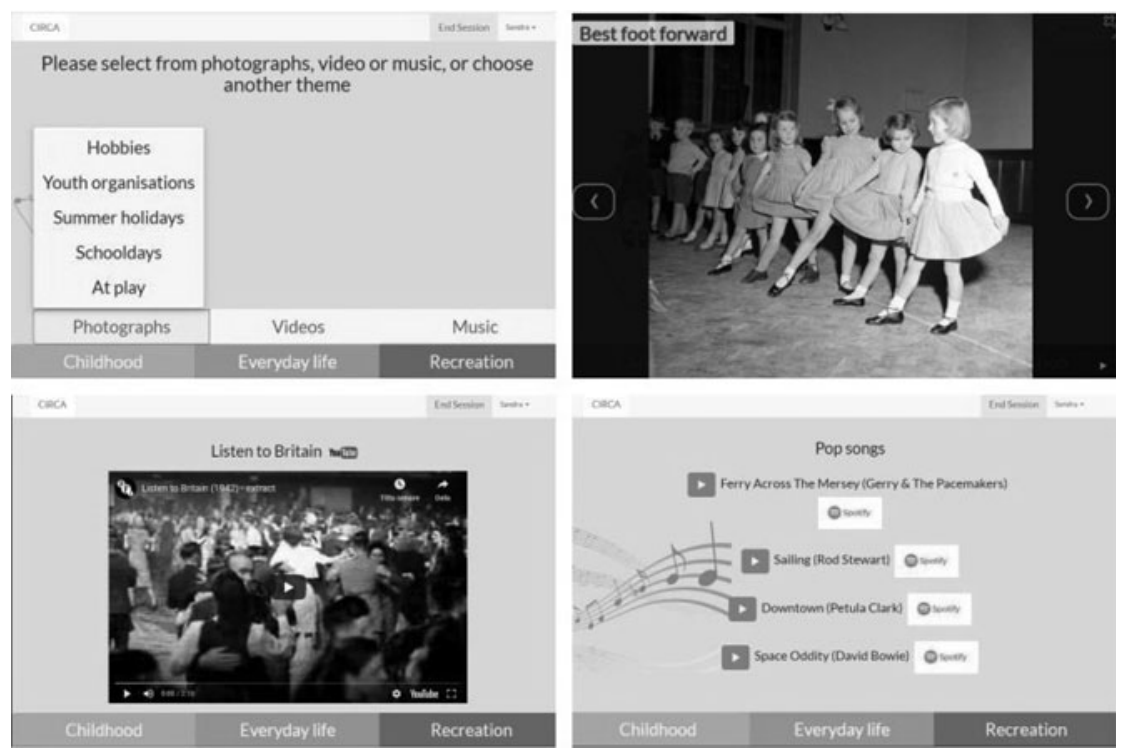

Figure 1. CIRCA is filled with generic material and is divided into three general categories, photos, films and music, and their sub-categories (topics). When choosing a topic, a picture, film clip or music tune is randomly shown on the screen to enjoy and talk about.
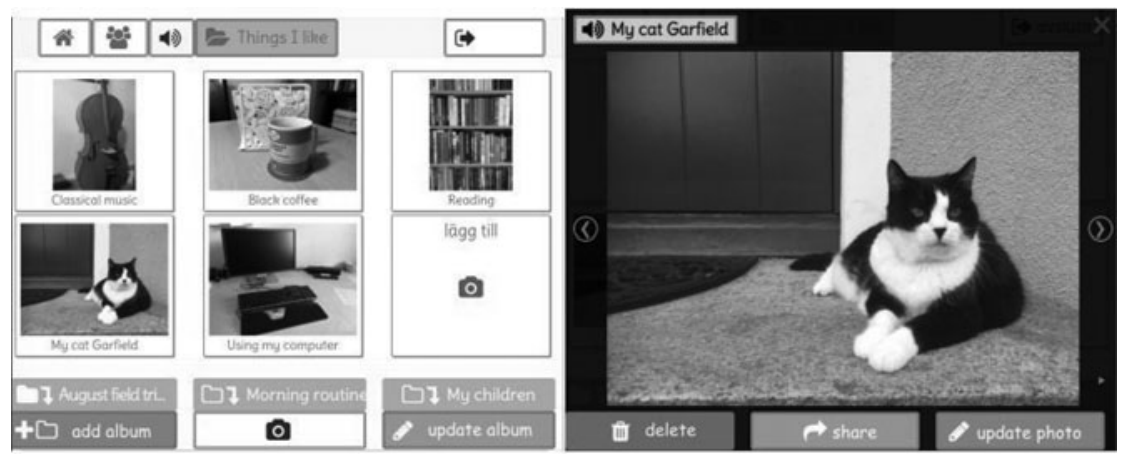

Figure 2. CIRCUS can be filled with personal material, such as photos and films, in different folders. It also contains speech synthesis and a sharing function.

dyads of women with dementia and their carers, all using both CIRCA and CIRCUS, also found evidence that people with dementia and their carers would benefit from this technology (Ferm et al., 2020).

However, there is still a knowledge gap regarding the effects of using digital reminiscence interventions, such as CIRCA and CIRCUS, that are designed to support elderly people with cognitive difficulties, such as dementia, and their communication partners.

The main purpose of this intervention study was to investigate the effects on all participants and on quality of life for people with dementia. The purpose is thus divided into two parts, with associated research questions: 
(1) Investigate the extent to which quality of life for people with dementia differed before and after the use of digital communication aids, measured using EQ-5D and QoL-AD, respectively.

(2) Examine the effect of using digital communication aids, divided into the following sub-questions:

(a) What was the impact on the health and wellbeing post-intervention for people with dementia, care-givers and relatives?

(b) Is there any correlation between the perceived usefulness of the digital communication aid and the impact on the health and wellbeing of people with dementia, care-givers and relatives?

(c) Is there any correlation between the care-givers' rating of the usefulness of the digital communication aid and their overall satisfaction with technology?

\section{Methods}

The inclusion criteria of this study were that people with dementia should (a) be over the age of 55, (b) not have previous cognitive difficulties following another diagnosis, (c) have experienced cognitive difficulties or been given an age-related dementia diagnosis, (d) need support in their daily lives from a care-giver or relative, (e) have access to at least one care-giver or relative to support their participation, and (f) be capable of giving their informed consent after receiving accessible information about the study. Determination of the sample size was guided by the study funder and by the project's budget parameters and experience with former surveys. A convenience sample was used, comprising participants recruited through various channels. To reach management and staff, all local representatives in a regional network for dementia nurses were informed about the study and spread the information to care homes and daily activity centres throughout the region where people with dementia participated. To reach people with dementia and their relatives individually, information was spread through Dart's Web and social media channels as well as through open lectures and workshops where interested care-givers and relatives got in direct contact with the project team. Recruitment of participants commenced after ethical approval. All participants matching the inclusion criteria were invited to participate in the study. The type or degree of dementia of the participants was not taken into account, although the majority of the participants received some type of dementia care, which means that a prior dementia assessment was made. The inclusion criterion for the care-givers and relatives was that they had regular contact with the people with dementia who participated in the project.

In total, 253 people signed up to participate in the study. Out of these, 50 people with dementia, 66 care-givers and two relatives had to be excluded for one of two reasons: (a) the participants had given their written consent to participate, but did not complete all the questionnaires, or (b) their data had been collected before the official questionnaires of the IN LIFE project were supplemented by Horizon 2020, the European Union's research and innovation framework programme, which meant that data from these participants did not comply with the project's data collection and could not be compared.

The participants who completed initial demographic questionnaires comprised 118 people with dementia, 187 care-givers and nine relatives. The majority of 
Table 1. Background data of participants, including the living situation of the people with dementia

\begin{tabular}{|c|c|c|c|}
\hline & People with dementia & Care-givers & Relatives \\
\hline $\mathrm{N}$ & 118 & 187 & 9 \\
\hline \multicolumn{4}{|l|}{ Gender: } \\
\hline Male & 41 & 13 & 2 \\
\hline Female & 77 & 174 & 7 \\
\hline Age range & $57-101$ & $17-66$ & $51-67$ \\
\hline Mean age & 84 & 45 & 56 \\
\hline \multicolumn{4}{|l|}{ Living situation: } \\
\hline Live alone & 40 & & \\
\hline Live with family & 2 & & \\
\hline Live with partner & 2 & & \\
\hline Care home & 13 & & \\
\hline No information & 20 & & \\
\hline
\end{tabular}

Note: $\mathrm{N}=314$ (56 male, 258 female).

participants in all groups were women. The participants with dementia had a mean age of 84 while the care-givers and relatives had one of 45 and 56, respectively (see Table 1). Participants with dementia were asked about their living situation. A significant number were living alone, but all participants with dementia needed support in their daily life and had various kinds of services.

\section{IN LIFE intervention}

Participants were assigned to either the CIRCA or the CIRCUS digital communication aid for a trial period. This period lasted between 4 and 12 weeks depending on the supporting care-givers or relatives' possibility of devoting time to the project. The project provided the participants with a tablet with an internet connection and a personal login code. The elderly people with dementia, their care-givers and their relatives all participated when testing CIRCA. The CIRCUS testing had to commence late due to unforeseen delays in the application development. Because of this delay, the project limited testing to a few people with dementia and their caregivers who expressed interest in CIRCUS specifically.

All participants in the study received oral, written and Web-based information regarding the IN LIFE project, along with information about how they could use the digital communication aids. The information was in an easy-to-read format and included pictorial support. Care-givers and relatives received an initial workshop with demonstrations of the communication aids. All the participants used the digital communication aids at care homes, day care facilities, hospitals or homes.

\section{Procedure}

All participants were provided with information about the study, both orally and in easy-to-read format with pictorial support, before the intervention period started. 
All participants gave their informed consent, either in writing or orally witnessed by a staff member. Questionnaires were distributed both before and after participation in the project. The participants could choose to fill them in directly online on the tablets used in the trials or on paper which was collected by the researchers. Only the EQ-5D survey could not be digitalised due to copyright issues. The questionnaires developed for people with dementia had pictorial support and were written in an easy-to-read format. Carers and relatives provided support as the participants with dementia answered the questions. The questionnaires were completed immediately after the trial period to make sure as much as possible of the experiences was captured.

In three of the questionnaires, the questions covered satisfaction with technology, the rating of the digital apps, their usefulness, and their impact on health and wellbeing. Five-point scales were used.

Following guidelines from Horizon 2020, two additional surveys were used to measure the quality of life of people with dementia, the EQ-5D and QoL-AD questionnaires. Using two surveys is recommended as they complement each other, one being generic and the other disease-specific (Ades et al., 2013).

EQ-5D contains five dimensions: Mobility, Self-care, Usual activities, Pain/discomfort and Anxiety/depression, where a low score indicates good quality of life. The answers are given on a scale of 1-5, which produces a score of 5-25 (Fayers and Machin, 2000). A 20-centimetre visual analogue scale from 0 to 100 , where the respondents mark their current state of health, is also part of the survey, with a high score indicating good quality of life. An overall improvement was not anticipated, for instance in the dimension of mobility, in view of the neurodegenerative nature of dementia.

QoL-AD contains 13 dimensions, with each dimension rated on a four-point scale (poor, fair, good and excellent). The dimensions in QoL-AD are: Physical health, Energy, Mood, Living situation, Memory, Family, Marriage, Friends, Self as a whole, Life as a whole, Ability to do chores around the house, Ability to do things for fun and Money (Selai et al., 2001; Sloane et al., 2005). The survey produces a total score of 13-52, with a high score indicating good quality of life (Sloane et al., 2005; Wolak-Thierry et al., 2014).

Given the nature of the trial setup and the way the questionnaires were conducted, the results show the participant's self-reported perceptions of usefulness rather than an external measure that would have required observations from the researchers.

\section{Data analysis}

The Statistical Package for the Social Sciences version 25.0 was used for data and statistical analyses. Since ordinal data were present and we suspected that data were not normally distributed, non-parametric data analysis tests were conducted. For all the statistics, $p<0.05$ or $p<0.01$ was selected. When analysing quality of life of people with dementia, the Wilcoxon signed-rank test was used for the total pre-intervention and post-intervention scores. For people with dementia who did not fill in one to two dimensions out of a total of 13 , the missing dimensions were supplemented by average scores, which were then added to calculate the total score (Hoe et al., 2006).

To analyse the impact on all the participants' health and wellbeing after using the digital communication aids, descriptive statistics were used based on the 
CIRCA and CIRCUS evaluation questionnaires. Chi-square test and Spearman's correlation analysis were used when analysing the relationship between the participants' rating of the usefulness of the digital communication aids and their impact on their health and wellbeing, as well as the relationship between the care-givers' rating of their satisfaction with technology and their rating of the usefulness of the communication aids.

\section{Results}

\section{Quality of life for people with dementia measured using EQ-5D}

The total EQ-5D score, where a low score indicates good quality of life, revealed a significant improvement in quality of life with the result: $\mathrm{N}=45, z=2.87, p<$ 0.05 . Prior to participation in the IN LIFE project, the people with dementia scored median $(\mathrm{Md})=13$ (standard deviation $(\mathrm{SD})=0.06)$ and after participation they scored $\mathrm{Md}=12(\mathrm{SD}=4.48)$. For the five individual dimensions in the questionnaire, Mobility $(p=0.073)$, Self-care $(p=0.505)$, Usual activities $(p=0.060)$, Pain/discomfort $(p=0.973)$ and Anxiety/depression $(p=0.653)$, reduced scores were also revealed, although the reduction was not significant. People with dementia were also required to rate their current state of health according to a visual analogue scale in percentage terms from 0 to 100 , where a high rating indicates a better state of health. The results showed that there was an increase in the ratings of people with dementia before and after participation in the IN LIFE project, although the difference was not significant $(z=1.536$, $p=0.125)$.

\section{Quality of life for people with dementia measured using QOL-AD}

The total score using QoL-AD, where a high score indicates good quality of life, revealed an improvement in quality of life for people with dementia although the results were not significant $(\mathrm{N}=30, z=0.496, p=0.620)$. Prior to participation in the IN LIFE project, people with dementia scored $\mathrm{Md}=31.0(\mathrm{SD}=4.4)$ and after participation they scored $\mathrm{Md}=31.0(\mathrm{SD}=4.9)$.

For three of the 13 dimensions, there were significant differences between the results. For people with dementia $(\mathrm{N}=49)$, the result for Memory before participation was $\mathrm{Md}=1.0(\mathrm{SD}=0.73)$ and after participation the result was $\mathrm{Md}=1.0$ $(\mathrm{SD}=0.67)$, which was a significant memory deterioration $(z=2.556, p=0.011)$. The result for Physical health $(\mathrm{N}=56)$ before participation was $\mathrm{Md}=2(\mathrm{SD}=$ $0.82)$ and after participation the result was $\mathrm{Md}=2(\mathrm{SD}=0.59)$, which is also a significant deterioration $(z=3.087, p=0.002)$. The result for Ability to do things for fun $(\mathrm{N}=43)$ before participation was $\mathrm{Md}=2(\mathrm{SD}=0.6)$ and after participation it was $\mathrm{Md}=2(\mathrm{SD}=0.69)$, which represents a significant increase in the potential to do things for fun $(z=2.13, p=0.033)$.

The results for other dimensions were not significant: Energy $(\mathrm{N}=57, p=0.866)$, Mood $(\mathrm{N}=59, p=0.64)$, Living situation $(\mathrm{N}=57, p=0.127)$, Family $(\mathrm{N}=55$, $p=0.634)$, Marriage $(\mathrm{N}=17, p=0.272)$, Friends $(\mathrm{N}=39, p=0.355)$, Self as a whole $(\mathrm{N}=52, p=0.317)$, Life as a whole $(\mathrm{N}=52, p=0.317)$, Ability to do chores around the house $(\mathrm{N}=30, p=0.805)$ and Money $(\mathrm{N}=28, p=0.237)$. 


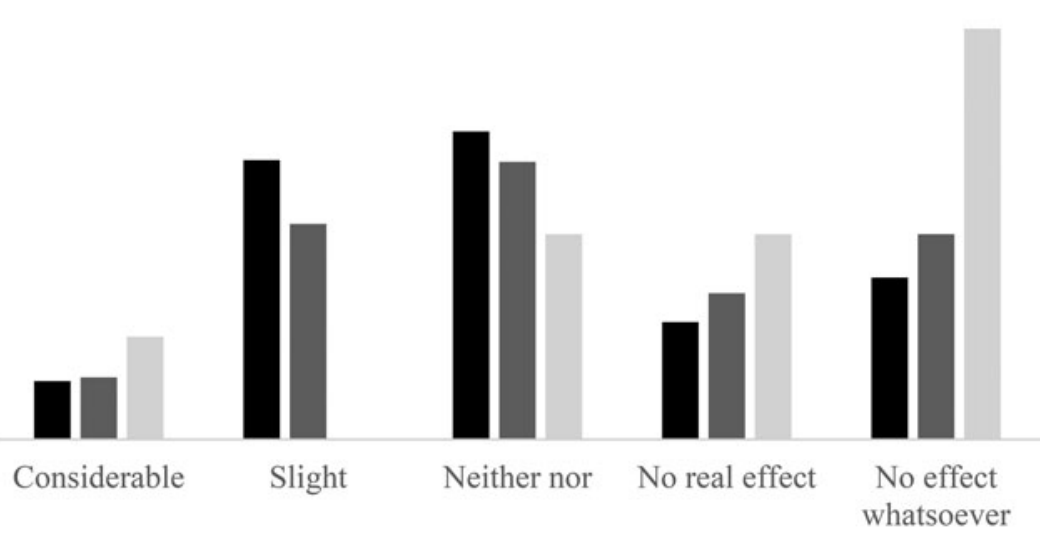

- People with dementia $\quad$ Caregivers $\|$ Relatives

Figure 3. Frequency spread for the participants' rating of the effect of CIRCA on their health and wellbeing.

\section{The effects on the participants' health and wellbeing following use of the Web-based communication aids}

As seen in Figure 3, the average rating of CIRCA's effect on their health and wellbeing for people with dementia $(\mathrm{N}=63)$ was Neither nor (mean $=3.05, \mathrm{SD}=1.18)$. The average rating of the care-givers $(\mathrm{N}=120)$ produced the same result Neither nor (mean $=3.28, \mathrm{SD}=1.25$ ) and that of relatives $(\mathrm{N}=9)$ was No real effect $($ mean $=3.89, \mathrm{SD}=1.36)$.

Figure 4 shows that for people with dementia $(\mathrm{N}=9)$, the average rating of the effect of CIRCUS on their health and wellbeing was No real effect (mean $=4.33$, SD $=1.12)$. For the care-givers $(\mathrm{N}=42)$, the average rating was Neither nor (mean = 3.1, $\mathrm{SD}=1.27$ ). As the relatives did not undergo CIRCUS testing, no similar analysis was made for the remaining participants.

\section{Correlation between the participants' rating of the usefulness of the Web-based communication aids and the effect on their health and wellbeing}

Using Spearman's correlation analysis, the rating by people with dementia $(\mathrm{N}=63)$ of the usefulness of CIRCA (mean $=2.57, \mathrm{SD}=1.12$ ) and the effect on their health and wellbeing following intervention with CIRCA ( mean $=3.05, \mathrm{SD}=1.18$ ), showed a positive correlation $(r=0.743, p<0.01)$. A chi-square test also revealed a positive correlation between usefulness and effect on the health and wellbeing of people with dementia $\left(\chi^{2}=62.419\right.$, degrees of freedom $\left.(\mathrm{df})=16, p<0.01\right)$. In the case of people with dementia $(\mathrm{N}=9)$ who used CIRCUS, there was no significant correlation $(r=0.640, p=0.063)$ between their rating of usefulness (mean $=3.44, \mathrm{SD}=$ 1.51 ) and the effect on their health and wellbeing (mean $=4.33, \mathrm{SD}=1.12$ ).

With Spearman's correlation analysis, the care-givers' $(\mathrm{N}=120)$ rating of the usefulness (mean $=2.37, \mathrm{SD}=1.23$ ) and the effect on their health and wellbeing following use of CIRCA (mean $=3.28, \mathrm{SD}=1.25$ ) showed a significant correlation, and 
20

10

0

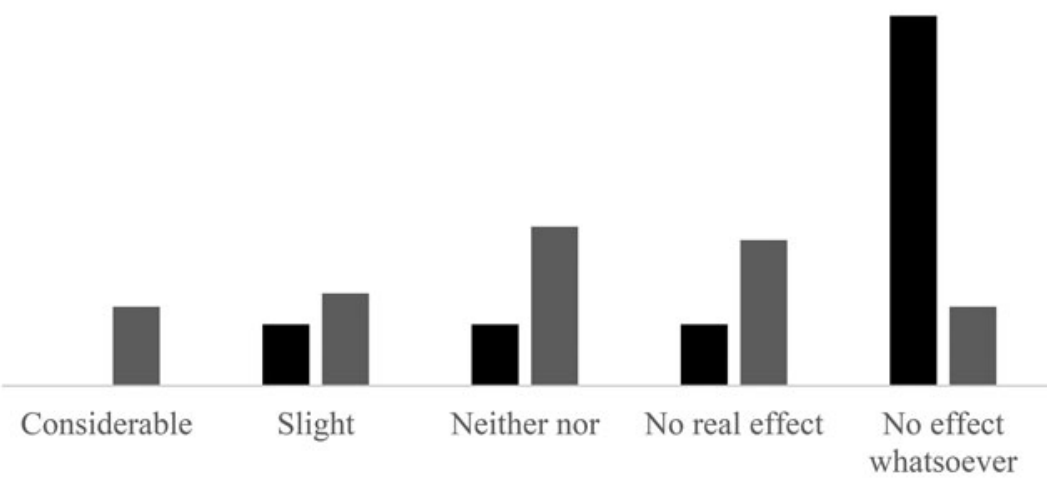

- People with dementia Caregivers

Figure 4. Frequency spread for the participants' rating of the effect of CIRCUS on their health and wellbeing.

it was slightly positive $(r=0.370, p<0.01)$. In the case of the chi-square test, a significant correlation was also noted between the usefulness of CIRCA and the effect on the care-givers' health and wellbeing $\left(\chi^{2}=32.846, \mathrm{df}=16, p<0.01\right)$. The correlation between the care-givers' $(\mathrm{N}=42)$ rated usefulness of CIRCUS (mean $=1.78$, $\mathrm{SD}=1.09)$ and the effect on their health and wellbeing (mean $=3.1, \mathrm{SD}=1.27)$ was not significant $(r=0.034, p=0.830)$.

As seen in Table 2, relatives' $(\mathrm{N}=9)$ rating of the usefulness of CIRCA (mean = $3.22, \mathrm{SD}=1.2)$ and the effect on their health and wellbeing $($ mean $=3.05, \mathrm{SD}=$ 1.18) did not reveal any significant correlation $(r=0.436, p=0.240)$ with Spearman's correlation analysis. Neither did the chi-square test $(p=0.116)$.

\section{Correlation between the care-givers' rating of the usefulness of the Web-based communication aids and a rating of their satisfaction with the technology}

The care-givers' $(\mathrm{N}=113)$ rating of the usefulness of CIRCA was Usable to some degree $(\mathrm{Md}=2, \mathrm{SD}=1.23)$ and the rating of their satisfaction with the technology was Quite satisfied $(\mathrm{Md}=3, \mathrm{SD}=0.89)$. Using Spearman's correlation analysis, a significant positive correlation was noted between the care-givers' rating of their satisfaction with technology and their rating of the usefulness of CIRCA ( $r=$ $0.301, p=0.001$ ). In the case of the chi-square test, a correlation was noted between the care-givers' rating of usefulness and their satisfaction with the technology $\left(\chi^{2}=28.087, \mathrm{df}=16, p<0.05\right)$. Table 3 shows the details of the care-givers' rated usefulness and the covariation with their satisfaction with the technology.

The care-givers' $(\mathrm{N}=49)$ rating of the usability of CIRCUS was Usable to some degree $(\mathrm{Md}=1, \mathrm{SD}=1.09)$ and the rating of their satisfaction with the technology was Satisfied $(\mathrm{Md}=2, \mathrm{SD}=0.71)$. Spearman's correlation analysis revealed no correlation between the care-givers' satisfaction with the technology and their rating of the usability of CIRCUS $(r=0.167, p=0.252)$, and neither did the chi-square test $\left(\chi^{2}=11.182, \mathrm{df}=8, p=0.192\right)$. 
Table 2. Correlation between the participants' health and wellbeing and the usefulness of CIRCA with Spearman's correlation analysis and chi-square test

\begin{tabular}{lcc}
\hline Participants & $r$ & $p$ \\
\hline People with dementia & 0.720 & $0.000^{\star}$ \\
Care-givers & 0.370 & $0.000^{\star}$ \\
Relatives & 0.436 & 0.240 \\
\hline
\end{tabular}

Significance level: ${ }^{*} \mathrm{p}<0.01$.

Table 3. Covariation of care-givers' satisfaction with the technology and their rating of the usefulness of CIRCA

\begin{tabular}{|c|c|c|c|c|c|}
\hline \multirow[b]{2}{*}{$\begin{array}{l}\text { Rating of } \\
\text { usefuless }\end{array}$} & \multicolumn{5}{|c|}{ Satisfaction with technology } \\
\hline & $\begin{array}{l}\text { Very } \\
\text { satisfied }\end{array}$ & Satisfied & $\begin{array}{l}\text { Quite } \\
\text { satisfied }\end{array}$ & $\begin{array}{l}\text { Not particularly } \\
\text { satisfied }\end{array}$ & $\begin{array}{l}\text { Not at all } \\
\text { satisfied }\end{array}$ \\
\hline \multirow[t]{2}{*}{$\mathrm{N}$} & 26 & 24 & 59 & 3 & 1 \\
\hline & \multicolumn{5}{|c|}{ Percentages } \\
\hline Very usable & 50 & 54.2 & 18.6 & 33.3 & 0 \\
\hline $\begin{array}{l}\text { Usable to } \\
\text { some degree }\end{array}$ & 11.5 & 25 & $20.3^{1}$ & 0 & 0 \\
\hline Neither nor & 23.1 & 16.6 & 39 & 66.7 & 0 \\
\hline $\begin{array}{l}\text { Not very } \\
\text { usable }\end{array}$ & 7.7 & 4.2 & 13.6 & 0 & 100 \\
\hline $\begin{array}{l}\text { Not usable at } \\
\text { all }\end{array}$ & 7.7 & 0 & 8.5 & 0 & 0 \\
\hline
\end{tabular}

Note: 1 . The most commonly reported rate.

\section{Discussion}

The first purpose of this study was to investigate the extent to which quality of life for people with dementia differed before and after the use of digital communication aids, measured using EQ-5D and QoL-AD, respectively. As a consequence of dementia, both memory and general health deteriorate as the disease progresses (Tang and Robinson, 2013). Hypothetically, this was also the case for the participants in the present study during the intervention period. However, it was noted in this study, when measured using EQ-5D, that quality of life improved for people with dementia, and when measured using QoL-AD, that the ability to do things for fun improved. It is reasonable to assume that the number of opportunities for social interaction and activities for people with dementia increased as they were involved in the present intervention using CIRCA or CIRCUS.

The second purpose of this study was to examine the effect of using digital communication aids, and the first sub-question was: What was the impact on the health and wellbeing post-intervention for people with dementia, care-givers and relatives? The participants in the study reported that use of Web-based communication aids had 
a neutral effect on health and wellbeing. Previous research shows that Web-based aids that were intended to promote communication and interaction between people with dementia and their communication partners resulted in improved health and wellbeing for all (Alm et al., 2004; Astell et al., 2010; Lopes et al., 2016; Goffe and Karlsson, 2017). The use of technology can enable and stimulate interaction between people with dementia and those who care for them (Ferm et al., 2020). A possible explanation for the lack of significance in the present study is that care-givers or relatives of people with dementia did not have enough time or felt stressed in conjunction with the intervention, and thus did not have the opportunity to reflect on whether it had any effect on their own health and wellbeing. Research has shown that there is a correlation between improved quality of life for people with dementia and when the people around them feel less stressed (Orgeta et al., 2015).

More time to use the Web-based communication aids together with people with dementia might have had a more positive effect on the care-givers' health and wellbeing.

The second sub-question was: Is there any correlation between the perceived usefulness of the digital communication aid and the impact on the health and wellbeing of people with dementia, care-givers and relatives? In the present study, a correlation was noted between the participants' rating of the usefulness of CIRCA and the effect of CIRCA on their health and wellbeing. However, the results showed no corresponding significant effect on health and wellbeing related to the use of CIRCUS. The main reason for the results relating to the effect of the Web-based communication aids on the participants' health and wellbeing could be explained by their ability to use the aids. This correlation has also emerged in previous research (Astell et al., 2010; Goffe and Karlsson, 2017). This could explain the differences between the effect on health and wellbeing of intervention with CIRCA and intervention with CIRCUS. As stated previously, CIRCUS is a personal Web-based communication aid where the participants themselves are required to add their own material. There are thus greater demands on the users of this intervention compared with the users of CIRCA, which is already filled with generic material. Care-givers already have a high workload and they generally have lowpaid jobs, long working days, few benefits, and are subject to occupational injury and depression (Deutschman, 2000). A potential risk of intervention via a tablet or a computer could be that it leads to new demands on the care-givers or relatives of people with dementia, which could increase their burden instead of alleviating it (Kerkhof et al., 2016).

The third sub-question was: Is there any correlation between the care-givers' rating of the usefulness of the digital communication aid and their overall satisfaction with technology? Previous research into reminiscence intervention has reported that there are several benefits with the digital multimedia format. This is particularly the case when the care-givers feel that the people they care for can make use of the system, which was shown in previous research into CIRCA (Alm et al., 2004). Our study shows that there was no significant correlation for CIRCUS, which may be due to the previously discussed requirement of individual adaptions. The correlation for CIRCA was deemed higher, which may have to do with the fact that it can be used without preparations in different settings.

Qualitative research into CIRCA has revealed that CIRCA supports relationships between care-givers and people with dementia by creating situations that involve 
engaging in social interaction (Astell et al., 2010). Qualitative research into CIRCUS has produced similar results, where all care-givers who participated in the study were positively disposed to using CIRCUS, although it was difficult for people with dementia to interact with the system independently (Goffe and Karlsson, 2017). It was previously believed that people with dementia were not capable of using new technology, or they would find it very difficult to learn how to use it, as it was assumed that the technology is too complicated or that elderly people are not familiar with it (Orpwood et al., 2010). However, several studies have shown that people with dementia are capable of learning how to use new technology (Thivierge et al., 2008; Imbeault et al., 2013).

\section{Limitations of the study}

A number of limitations arose in the present study when analysing the participants' experiences of Web-based communication aids. The first limitation was the absence of a control group and lack of power analysis as well as sensitivity analysis, which impedes the potential to distinguish the true effect.

The second limitation for the analysis was the drop-out rate, the main reasons being the care-givers' and relatives' ability to complete the questionnaires and the fact that the questionnaire had already been changed to some extent when data collection commenced. The high number of excluded participants and dropouts in the case of the QoL-AD questionnaire could be the reason the results were not significant. EQ-5D and QoL-AD correlated significantly with each other with regard to their reliability. However, EQ-5D demonstrates stronger inter-assessor reliability between people with dementia and their representatives, i.e. when the quality of life questionnaire for the person with dementia is filled in by other people (Aguirre et al., 2016). Since this was the case in the present study, EQ-5D may work better than specific quality-of-life questionnaire metrics.

The third limitation was a lack of data in the present intervention study relating to the type and degree of dementia among the participants which is a key factor in distinguishing with which group the intervention works best. The lack of this information could thus affect the results as there could be major differences in how people with dementia rated their quality of life depending on their difficulties. This could mean that the results obtained in the present study are not representative of all people with dementia. The inclusion criteria for participating in the study mean that all participants were assessed to have dementia, but no individual assessment was possible to carry out in the parameters of this study. Furthermore, dementia is a degenerative disease and assessing improvements in disease status reported through quality-of-life questionnaires completed by people with dementia with the aid of supportive care-givers or relatives is problematic (Arons et al., 2013).

A fourth limitation was that the study did not distinguish the results according to the setting in which the participant used the digital communication aid (e.g. at a care home or in their own home), which could have given more information whether or not the setting was a key factor for the intervention. These limitations are all related to the fact that the present study was part of a larger project, where the design and methodology were set and not possible to adjust for a single partner.

A fifth limitation was that this study aimed to investigate both the experiences of relatives and care-givers, but got a large overweight of care-givers among the 
participants. One reason for this was that the main part of the recruitment was obtained through networks of professionals. It was difficult to reach the people with dementia themselves and their family members, even though efforts were made through user organisations, social media, and open lectures and workshops. The participants with dementia received care in their home or lived in care homes and the contact with the researchers was mediated via the carers. Even though carers were encouraged to invite relatives to participate, there was a sparse response. The reason for this is unknown to us but we can suspect that this information got lost in the communication between the staff and the relatives, or that people with dementia in care homes may not have frequent contact with relatives.

There could be a number of reasons why the effect on health and wellbeing was reported as neutral in comparison with the quality-of-life results for people with dementia. One reason could be that they interpreted health and wellbeing in line with the World Health Organization's 1949 classification, in which good health is described as a condition of complete physical, mental and social wellbeing. According to previous research, this could be problematic as complete wellbeing is difficult to achieve and health-promoting activities, as is the case with the Web-based communication aids in the present study, could be easily misinterpreted as helping to counteract the disease rather than promoting the person's health and wellbeing (Card, 2017). Another reason could be that the intervention was not sufficiently intensive to have any effect on the participants' health and wellbeing.

\section{Future studies}

Clear intervention guidelines are important as the intervention results may be affected by many factors, for instance, the intensity of the intervention. Both the degenerative nature of dementia and the involvement of support from carers and relatives must be considered in order to design robust intervention studies. To exclude any bias, future research is needed in order to focus on identifying factors that affect the health and wellbeing of people with dementia and their communication partners. For example, we suggest conducting separate studies to analyse session data and investigate whether the intensity of usage correlates to the level of selfreported satisfaction. Furthermore, future research ought to place more emphasis on CIRCUS and investigate whether the results would be different if the users had received more training in how to use the different functions in CIRCUS. In future studies, it would be relevant to look at the appropriate length of intervention period for the use of digital reminiscing aids to give effect. It would also be interesting to evaluate if the living situation and setting for intervention affected the results.

\section{Conclusion}

The present intervention study is a contribution to highlighting the significance of Web-based communication aids for people with dementia and their care-givers and relatives. It has provided further information about positive effects of Web-based communication aids on quality of life for people with dementia. A correlation between the usefulness of Web-based communication aids and their perceived effect on the participants' health and wellbeing was also noted. The study thus 
provides further knowledge to professionals and care-givers in relation to people with dementia. The study highlights that Web-based communication aids may be beneficial as they have a positive effect on quality of life for people with dementia. The Web-based communication aids in the study appear to be useful and have a perceived impact on the health and wellbeing of people with dementia and their care-givers and relatives. Web-based communication aids therefore appear to support and promote social interaction between people with dementia and their communication partners. The results of the present intervention study provide a basis for the use of Web-based communication aids to support social interaction and to become an integral part of E-health.

Acknowledgements. The authors wish to thank the participants for sharing their experiences and time.

Author contributions. SD, MB and $\mathrm{KL}$ are responsible for the design and the organisation of data collection. MBN and J-AS are responsible for the analysis and interpretation of the data and for the draughting of this article under the supervision of KL. SD and MB are responsible for revising this article for content and for getting it into a state ready for submission.

Financial support. The IN LIFE project was funded by the European Commission under the Horizon 2020 programme (grant agreement number 643442). The European Commission played no role in the design, execution, analysis or interpretation of the data or writing of the study.

Conflict of interest. The authors declare no conflicts of interest.

Ethical standards. The project was approved by the regional ethical review board in Linköping (reference number 2015/162-31) before data collection commenced. People with dementia were provided with accessible information about the study and consent forms. All participants provided informed consent.

\section{References}

Abrahamson K, Clark D, Perkins A and Arling G (2012) Does cognitive impairment influence quality of life among nursing home residents? The Gerontologist 52, 632-640.

Ades AE, Lu G and Madan J (2013) Which health-related quality-of-life outcome when planning randomized trials: Disease-specific or generic, or both? A common factor model. Value in Health 16(1), 185194.

Aguirre E, Kang S, Hoare Z, Edwards R and Orrell T (2016) How does the EQ-5D perform when measuring quality of life in dementia against two other dementia-specific outcome measures? Quality of Life Research 25, 45-49.

Alm N, Astell A, Ellis M, Dye R, Gowans G and Campbell J (2004) A cognitive prosthesis and communication support for people with dementia. Neuropsychological Rehabilitation 14, 117-134.

Anderson L, Prohaska T, Lazar A, Thompson H and Demiris G (2014) A systematic review of the use of technology for reminiscence therapy. Health Education \& Behavior 41, 51S-61S.

Arons A, Krabbe P, Scholzel-Dorenbos C, Van der Wilt G and Rikkert M (2013) Quality of life in dementia: a study on proxy bias. BMC Medical Research Methodology 13, 110.

Astell AJ, Ellis M, Alm N, Dye R, Gowans G and Campbell J (2005) Using hypermedia to support communication in Alzheimer's disease: the CIRCA project. In Proceedings of Foundations of Augmented Cognition 7th International Conference, AC 2013, Held as Part of HCI International 2013, Las Vegas, NV, USA, July 21-26, pp. 758-767.

Astell AJ, Ellis MP, Bernardi L, Alm N, Dye R, Gowans G and Campbell J (2010) Using a touch screen computer to support relationships between people with dementia and caregivers. Interacting with Computers 22, 267-275.

Astell AJ, Gradisek A, Bizjak J, Gjoreski H, Gams M, Goljuf K, Cabrera-Umpierrez MF, Montalva JB, Karavidopoulou Y, Panou M, Touliou K, Kaklanis N, Stavrotheodoros S, Tzovaras D, Kaimakamis E, Laakso K, Buchholz M, Derbring S, Samuelsson C, Ekström A, Garcia A, Chamorro Mata J, Smith 
SK, Potter S, Tabak M, Dekker-van Weering M, Cossu-Ergecer F and Black B (2018) INLIFE Independent Living Support Functions for the Elderly: technology and pilot overview. In Chatzigiannakis I, Tobe Y, Novais P and Amft O (eds), Intelligent Environments 2018: The 14th International Conference on Intelligent Environments - IE'18. pp. 526-535.

Azoulay E, Kentish-Barnes N and Pochard F (2008) Health-related quality of life: an outcome variable in critical care survivors. Chest 133, 339-341.

Bleijlevens M, Stolt M, Stephan A, Zabalegui A, Saks K, Sutcliffe C, Lethin C, Soto ME and Zwakhalen S (2015) Changes in caregiver burden and health-related quality of life of informal caregivers of older people with dementia: evidence from the European RightTimePlaceCare prospective cohort study. Journal of Advanced Nursing 71, 1378-1391.

Bourgeois MS and Hickey EM (2007) Dementia. In Beukelman DR, Garrett KL and Yorkston KM (eds), Augmentative Communication Strategies for Adults with Acute or Chronic Medical Conditions. Baltimore, London, Sidney: Brookes, pp. 243-285.

Bourgeois M, Dijkstra K, Burgio L and Allen-Burge R (2001) Memory aids as augmentative and alternative communication strategy for nursing home residents with dementia. Augmentative \& Alternative Communication 17, 196-210.

Brooks R (1996) EuroQol: the current state of play. Health Policy 37, 53-72.

Card A (2017) Moving beyond the WHO definition of health: a new perspective for an aging world and the emerging era of value-based care. World Medical \& Health Policy 9, 127-137.

Clare L, Rowlands J, Bruce E, Surr C and Downs M (2008) The experience of living with dementia in residential care: an interpretative phenomenological analysis. The Gerontologist 48, 711-720.

Deutschman M (2000) What you hear when you listen to staff. Nursing Homes Long Term Care Management 49, 37-43.

Ducharme J and Geldmacher D (2011) Family quality of life in dementia: A qualitative approach to family-identified care priorities. Quality of Life Research: An International Journal of Quality of Life Aspects of Treatment, Care and Rehabilitation 20, 1331-1335.

Ericsson I, Hellström I and Kjellström S (2011) Sliding interactions: an ethnography about how people with dementia interact in housing with care for the elderly. Dementia 10, 523-538.

European Commission (2018) IN LIFE Project. INdependent LIving Support Functions for the Elderly (Grant agreement 643442). Available at https://cordis.europa.eu/project/id/643442.

Fayers P and Machin D (2000) Quality of Life Assessment, Analysis, and Interpretation. Chichester, UK: John Wiley.

Ferm U, Ekström A, Larsson E and Samuelsson C (2020) Tablet computer-supported conversation between people with dementia and their carers: technology as interactional focus. Universal Access in the Information Society. Available at https://link.springer.com/article/10.1007/s10209-020-00745-4.

Gauthier S, Rosa-Neto P, Morais JA and Webster C (2021) World Alzheimer Report 2021: Journeythrough the diagnosis of dementia. London, England: Alzheimer's Disease International.

Goffe F and Karlsson H (2017) High Technological Communication Aid in Dementia - An Interaction Analysis With and Without the Communication Aid CIRCUS. Available at http://hdl.handle.net/2077/ 53355.

Gowans G, Campbell J, Alm N, Dye R, Astell A and Ellis M (2004) Designing a multimedia conversation aid for reminiscence therapy in dementia care environments. In CHI'04 Extended Abstracts on Human Factors in Computing Systems. New York, NY: ACM, pp. 825-836.

Herdman M, Gudex C, Lloyd A, Janssen M, Kind P, Parkin D, Bonsel G and Badia X (2011) Development and preliminary testing of the new five-level version of EQ-5D (EQ-5D-5L). Quality of Life Research 20, 1727-1736.

Hoe J, Hancock G, Livingston M and Orrell J (2006) Quality of life of people with dementia in residential care homes. British Journal of Psychiatry 188, 460-464.

Imbeault H, Bier N, Pigot H, Gagnon L, Marcotte N, Fulop T and Giroux S (2013) Electronic organiser and Alzheimer's disease: fact or fiction? Neuropsychological Rehabilitation 24, 71-100.

Kerkhof Y, Graff M, Bergsma A, De Vocht H and Dröes R (2016) Better self-management and meaningful activities thanks to tablets? Development of a person-centered program to support people with mild dementia and their carers through use of hand-held touch screen devices. International Psychogeriatrics 28, 1917-1929. 
Lopes T, Afonso R and Ribeiro $\mathbf{O}$ (2016) A quasi-experimental study of a reminiscence program focused on autobiographical memory in institutionalized older adults with cognitive impairment. Archives of Gerontology and Geriatrics 66, 183-192.

Orgeta V, Edwards R, Hounsome B, Orrell M and Woods B (2015) The use of the EQ-5D as a measure of health-related quality of life in people with dementia and their carers. Quality of Life Research 24, 315-324.

Orpwood R, Chadd J, Howcroft A, Sixsmith J, Torrington G, Gibson G and Chalfont G (2010) Designing technology to improve quality of life for people with dementia: user-led approaches. Universal Access in the Information Society 9, 249-259.

Pearce A, Clare L and Pistrang N (2002) Managing sense of self: coping in the early stages of Alzheimer's disease. Dementia 1, 173-192.

Preston L, Marshall A and Bucks R (2007) Investigating the ways that older people cope with dementia: a qualitative study. Aging \& Mental Health 11, 131-143.

Prince M, Bryce R, Albanese E, Wimo A, Ribeiro W and Ferri CP (2013) The global prevalence of dementia: a systematic review and metaanalysis. Alzheimer's \& Dementia 1, 63-75.

Prince M, Wimo A, Guerchet M, Ali G-C, Wu Y-T and Prina M (2015) World Alzheimer Report 2015: The Global Impact of Dementia: An Analysis of Prevalence, Incidence, Cost and Trends. London: Alzheimer's Disease International. Available at https://www.alz.co.uk/research/WorldAlzheimerReport2015.pdf.

Selai C, Vaughan A, Harvey R and Logsdon R (2001) Using the QOL-AD in the UK. International Journal of Geriatric Psychiatry 16, 537-538.

Sloane P, Zimmerman S, Williams C and Reed P (2005) Evaluating the quality of life of long-term care residents with dementia. The Gerontologist 45, 37-49.

Smith ER, Broughton M, Baker R, Pachana NA, Angwin AJ, Humphreys MS, Mitchell L, Byrne GJ, Copland DA, Gallois C, Hegney D and Chenery HJ (2011) Memory and communication support in dementia: research-based strategies for caregivers. International Psychogeriatrics 23, 256-263.

Tang E and Robinson L (2013) Helping people to live well with dementia. InnovAiT: Education and Inspiration for General Practice 6, 754-762.

Thivierge S, Simard M, Jean L and Grandmaison E (2008) Errorless learning and spaced retrieval techniques to relearn instrumental activities of daily living in mild Alzheimer's disease: a case report study. Neuropsychiatric Disease and Treatment 4, 987-999.

University of Sheffield (2018) IN LIFE Tools. A Prototype. Available at https://catch.shef.ac.uk.

Välimäki T, Martikainen J, Hongisto K, Väätäinen S, Sintonen H and Koivisto A (2016) Impact of Alzheimer's disease on the family caregiver's long-term quality of life: results from an ALSOVA follow-up study. Quality of Life Research 25, 687-697.

Wolak-Thierry A, Novella J, Barbe C, Morrone I, Mahmoudi R and Jolly D (2014) Comparison of QoL-AD and DQoL in elderly with Alzheimer's disease. Aging \& Mental Health 19, 274-278.

Woods B, O'Philbin L, Farrell EM, Spector AE and Orrell M (2018) Reminiscence therapy for dementia. Cochrane Database of Systematic Reviews 2018, CD001120.

Cite this article: Derbring S, Barbos Nordström M, Svenningsson J-A, Ekström A, Ingebrand E, Samuelsson C, Laakso K, Buchholz M (2021). Effects of a digital reminiscing intervention on people with dementia and their care-givers and relatives. Ageing \& Society 1-18. https://doi.org/10.1017/ S0144686X21001446 